\title{
B. Hirt, H. Seyhan, M. Wagner, R. Zumhasch: Hand and wrist anatomy and biomechanics: a comprehensive guide
}

\section{Thieme 2016, 116 pp, 111 ill., Hardcover 69.99 EUR (D), 72.00 EUR (A), 80.00 CHF, ISBN: 978-3-13-205341-0}

\author{
Pierre Kehr ${ }^{1}$ - Alain G. Graftiaux ${ }^{1}$
}

Received: 15 May 2017/ Accepted: 30 May 2017/Published online: 13 June 2017

(C) Springer-Verlag France SAS 2017

The goal of this book is to treat together the anatomy and biomechanics with the hand and the wrist in such a way that the comprehension of various pathologies.

This book is divided into two great parts. The first relates to the static and functional anatomy of the hand and the wrist in the broad sense since the book begins with the radioulnar proximales and distal articulations, then the wrist, the inch, the palm of the hand and the fingers. The second part milked the anatomy through the skin allowing by a precise clinical examination to find a good amount of anatomical elements. The illustrations are many very clear and easy to understand. Notes are added making it possible to find the pathological correspondence of the described anatomical structures. An extremely interesting book which will impassion young people and young people to understand easily why pathologies, and their means of treatment.

Alain G. Graftiaux

Strasbourg

France

Compliance with ethical standards

Conflict of interest The author declares that he has no competing interests.

Pierre Kehr

pierre.kehr@gmail.com

1 Strasbourg, France 